\title{
FUSIÓN TOTALITARIA Y SEPARACIÓN UTÓPICA. Lectura de Emmanuel Lévinas y Miguel Abensour
}

\author{
Claudia Gutiérrez Olivares ${ }^{l}$
}

\begin{abstract}
RESUMEN: En el siguiente texto intentaremos elucidar la particular estructura social, que define la utopía en el pensamiento de Lévinas, enfatizando su antagonismo estructural con la forma social propia de la estructura totalitaria. Es nuestro interés el argumentar aquí, que la utopía levinasiana en cuanto forma social, se fundamenta sobre la matriz de la "separación intersubjetiva", y que bajo este respecto ella aparece como una dimensión radicalmente opuesta a la estructura social del totalitarismo, en donde la "separación intersubjetiva" es imposible. De una a la otra, el ser social se juega como separación, o bien, como aglutinación; mientras la utopía separa, el totalitarismo fusiona. Nuestro acercamiento será articulado con elementos de análisis aportados por el contundente trabajo de Miguel Abensour respecto a la utopía. Por ello, asumimos como nuestra la perspectiva de análisis críticopolítica de nuestro autor, según la cual, la crítica al totalitarismo resulta determinante para el despeje de la dimensión utópica.
\end{abstract}

PALABRAS CLAVES: Lévinas. Abensour. Totalitarismo. Utopía. Fenomenología.

\section{INTRODUCCIÓN}

En clara filiación arendtiana, Miguel Abensour define la política como una "[...] experiencia de la libertad" (2012, p.30), marcando así y de entrada una distancia irreconciliable con todo registro de la servidumbre o la dominación. La política, escribe Abensour, es “[...] lo contrario de la dominación, [es] una lucha continua contra la dominación” (p. 32)2. Bajo este respecto, el programa de Abensour en términos de una crítica de la política, y de la posibilidad de su renuevo, pasa necesariamente por una crítica de la dominación, en particular de la dominación totalitaria. Lo que permanece esencial en tal itinerario, es que la crítica de la dominación comprende al mismo tiempo un redescubrimiento de la cuestión de la emancipación y de la

\footnotetext{
${ }^{1}$ Departamento de Filosofía. Universidad de Chile. E-mail: calacello@hotmail.com. Este artículo forma parte del Proyecto de Investigación Conicyt Inserción no 79100008.

${ }^{2}$ Todas las citas de Lévinas y Abensour corresponden a las ediciones francesas, y han sido traducidas para la redacción de este artículo.
} 
utopía, pues "[...] los caminos de la emancipación pasan necesariamente, sino acaso exclusivamente, por esta crítica” (2002, p.32).

Miguel Abensour es un notable filósofo-lector y su filosofía se tempera y construye a través y con los textos de otros, otorgándole a su filosofía una fisionomía heterogénea y rica, y desde un punto de vista teórico, una gestualidad saludablemente provocadora. En este sentido, la apuesta de una filosofía política crítica de Abensour podemos trabajarla en términos de una trama de intertextualidades, en donde el nombre de Lévinas forma perfectamente parte de esa trama. Cabe preguntarse entonces, ¿en qué sentido puede Lévinas contribuir al renuevo de la política? ¿De qué manera Lévinas puede entroncarse, o no, con la crítica a la dominación totalitaria? Y lo que nos parece quizás más determinante, ¿en qué sentido esta crítica puede abrir, a su turno, un pasaje a la utopía y a la emancipación? ${ }^{3}$ ¿Cuáles son los elementos de análisis que pueden esclarecer la intuición de Abensour, a saber, que Lévinas piensa en clave de utopía y emancipación?

En el siguiente texto intentaremos elucidar la dimensión de la utopía en el pensamiento de Lévinas, su especificidad ligada a una cierta concepción de la socialidad, y en particular su antagonismo estructural con la forma social propia de la estructura totalitaria. Es nuestro interés el argumentar aquí, que la utopía levinasiana en cuanto forma social, se fundamenta sobre la matriz de la "separación intersubjetiva", y que bajo este respecto ella aparece como una dimensión radicalmente opuesta a la estructura social del totalitarismo, en donde la "separación intersubjetiva" es imposible. De una a la otra, el ser social se juega como separación, o bien, como aglutinación; mientras la utopía separa, el totalitarismo fusiona.

Nuestro acercamiento será articulado con algunos elementos de análisis aportados por el contundente trabajo de Miguel Abensour respecto a la utopía, y que como sabemos, no se agota en las líneas dedicadas a Lévinas. ${ }^{4}$ Por ello, asumimos como nuestra la perspectiva de análisis crítico-política de nuestro autor, según la cual, la crítica al totalitarismo resulta determinante para el despeje de la dimensión utópica. Este contrapunto crítico, a nuestro juicio presente desde la obra temprana en Lévinas, será explorado en particular, a

\footnotetext{
${ }^{3}$ En este texto trabajaremos exclusivamente la cuestión de la utopía.

${ }^{4}$ El trabajo con la cuestión de la utopía en Abensour, con la reconstrucción crítica de la inscripción política de ésta, y que parte con una relectura de los textos políticos de Marx, data de los ańos 70 . Para ello, ver: Abensour, Miguel (1973), "Histoire de l'utopie et le destin de sa critique I" en Textures 6-7. (1974), "Histoire de l'utopie et le destin de sa critique II" en Textures 8-9.
} 
través de lo que podemos llamar preliminarmente la "matriz claustrofóbica" propia, a nuestro juicio, del totalitarismo. Ella se decanta de los análisis fenomenológicos del hitlerismo, que es la particular perspectiva de análisis levinasiana. Abordada desde un análisis fenomenológico, el de Lévinas, esta matriz se nos presenta como portadora de un "régimen sentimental" o disposición afectiva particular, a saber, el del sometimiento, cuya especificidad consiste en obstruir todo pasaje a lo otro, todo signo y forma de alteridad. Inversamente, la posibilidad de salir de ese registro de la claustrofobia, ya lo veremos, coincide con el pasaje hacia lo otro, y en este sentido, la utopía en sentido levinasiano, parece ser el primer destino de esta salida. Bajo este respecto, podríamos aventurarnos a pensar, que la utopía moviliza otra trama sentimental, otro régimen afectivo, en la medida que ella es, según Abensour, la negación de la estructura totalitaria.

\section{SENTiMientos ELEMENTALES}

Tomemos como punto de partida el texto de 1934, Algunas reflexiones sobre la filosofía del hitlerismo, ${ }^{6}$ en cuyas páginas se juega una original crítica de la dominación totalitaria nazi. Esta crítica es original, pues no se expone como un análisis político o histórico del fenómeno totalitario, sino como una "fenomenología" (ABENSOUR, 1997a, p.28). El análisis fenomenológico desarrollado por Lévinas, no solo permite apreciar desde otro punto de vista la cuestión del hitlerismo, sino además intensifica el potencial hermenéutico de la fenomenología, permitiendo abordar el totalitarismo en términos de una fenomenología de los "sentimientos elementales" (LÉVINAS, 1997, p.7). ¿Hitlerismo y sentimiento? La posibilidad de la lectura en clave "sentimental" del hitlerismo, que queremos desarrollar aquí, puede encontrar su punto de arranque en el estatuto del sentimiento para los fenomenólogos. En efecto, si en fenomenología los sentimientos indican de manera privilegiada una situación particular del hombre en el mundo, los "sentimientos elementales" movilizados por el hitlerismo según Lévinas, habrían de referirnos igualmente

\footnotetext{
${ }^{5}$ La noción de "claustrofobia" se la debemos a Martine Leibovici, profesora de Paris VII, y a su conferencia (inédita) "Claustrophobie du soi et besoin d'excedance. Le "pathétique du liberalisme" selon Emmanuel Lévinas”. Esta conferencia se realizó en el marco del Coloquio Internacional Chile - Francia, Emancipación y movimientos sociales", y tuvo lugar los días 28-29 de agosto del 2012, en la Universidad Academia de Humanismo Cristiano, en Santiago.

${ }^{6}$ Texto cuya reedición de 1997, Éditions Payot \& Rivages, comprende el ensayo de Miguel Abensour "Le mal élémental".
} 
a una situación particular, y que tiene que ver con una concepción precisa del hombre y del mundo.

Como es cosa sabida, la fenomenología redefine la conciencia en términos de intencionalidad, inaugurando así el paso a una comprensión renovada de todos los procesos y caracteres que animan la vida de la consciencia. Los sentimientos son relevantes para la vida de la conciencia en cuanto ellos pueden ser dichos intencionales, y bajo este respecto ellos son portadores de un mundo, que refieren a un entrelazamiento inaugural y originario que describe la trama existencial de lo humano. Gracias a la fenomenología, el sentimiento adquiere una dignidad filosófica relevante, en la medida que describe un mundo intencional, el que "[...] no es un aglomerado de hechos sólo accesible a las ciencias de la naturaleza” (LÉVINAS, 2006a, p.97). El mundo intencional que descubre el sentimiento, es un mundo que desborda la Naturaleza y en este sentido, él puede articularse emotivamente, bellamente, horrorosamente, rítmicamente, etc.; como trama de "[...] epítetos flotantes" (RICEUR, 2004, p.317), se trata de un mundo tejido de "[...] cosas interesantes y aburridas, útiles e inútiles, bellas y feas, amadas y odiadas, ridículas y angustiantes" (LÉVINAS, 2006a, p.97), de las cuales el sentimiento testimonia. Por ello, el sentimiento deja de ser un simple estado, cuya descripción se agota en los límites de una naturaleza fisiológica; él permite romper con una comprensión naturalista de lo humano, capaz de pensar al hombre según las determinaciones de la cosa. Es por sobre todo gracias al concepto de intencionalidad, que apunta a un nuevo ideal de la humanidad del hombre, movilizando la idea de espíritu encarnado, que la fenomenología "[...] preserva a la persona” (LÉVINAS, 2001, p.168). De ahora en adelante, el sentimiento es por sobre todo la indicación de una relación, de un vínculo que liga ineludiblemente al hombre con $s u$ mundo. Trátese de náusea, angustia, vergüenza, miedo, inquietud, etc., los sentimientos en fenomenología traducen una relación de "inherencia" al mundo, es decir, dan cuenta de una estructura ontológica que entrama, que teje al hombre con su mundo. Así en el texto de 1931, "Friburgo, Husserl y la fenomenología”, Lévinas precisa que para los fenomenólogos, la

[...] convicción fundamental consiste en afirmar y respetar la especificidad de la relación con el mundo que lleva a cabo el sentimiento. Sostienen firmemente que hay relación, que los sentimientos como tales 'tienden hacia algo', que constituyen, como tales, nuestra trascendencia en relación con nosotros mismos, nuestra inherencia al mundo. (2006a, p.94). 
Teniendo a la vista estas cuestiones y las ricas posibilidades hermenéuticas del sentimiento, volvamos al texto de 1934. Aquí la intención de Lévinas fenomenólogo, es la de hacer emerger la trama sentimental que, en la estructura totalitaria, teje al hombre con su mundo. Esta trama, según Lévinas, da cuenta de "[...] sentimientos elementales" (1997, p.7). ¿En qué consiste lo elemental? Si los sentimientos testimonian un enlazamiento estructural con el mundo, ¿qué noción de mundo se puede atisbar aquí? ¿A qué refiere lo elemental? Nuestra hipótesis es que el orden de lo "elemental" denota las apuestas de una definición unidimensional y monista del ser humano y del mundo en su conjunto, y que en su radicalización deriva en una manipulación y sometimiento a ultranza de aquél, como si lo humano no fuese más que una cosa entre las cosas. Lo elemental en este sentido, se refiere a la reducción a un monismo concreto definiendo lo humano, que suprime su dimensión sintiente y espiritual, enfatizando su determinación de cosa extensa, y por ello mismo susceptible de dominación. De esta manera, como las cosas, lo humano se puede manipular, someter, apilar, destruir, e inventar, "si la raza no existe, hay que inventarla” (LÉVINAS, 1997, p.20) A este respecto, pueden resultar clarificadoras las palabras de Traian, uno de los personajes de La hora 25, y que ilustran perfectamente esta reducción del hombre a un concreto unidimensional y sin espíritu:

La sociedad no conoce más que algunas dimensiones del individuo. Pero el hombre integral, tomado individualmente como tal, no existe para ella [...] Sencillamente, no somos. Existimos únicamente en tanto que fracciones infinitesimales de una categoría. Tú, por ejemplo, no eres más que una ciudadana enemiga detenida en territorio alemán [...] No te reconoce más que gracias a esos trazos distintos y te trata en consecuencia con todo el grupo a que perteneces, de acuerdo con las reglas de la multiplicación, de la división o de la substracción. [...] El hombre de carne y hueso, capaz de alegría y sufrimiento, no existe; ésa es la causa de que nuestra detención, nuestro encarcelamiento y acaso mańana nuestra ejecución no pueda ser considerada como criminal. (GHEORGHIU, 1950, p.238-239).

Por otra parte, decíamos que el sentimiento elemental estriba en una concepción monista de la existencia, y que apunta a reducir la humanidad del hombre a un principio concreto, en donde el principio espiritual aparece tachado, o bien reducido a aquel. Para Lévinas, este principio es proporcional a la preponderancia de la matriz biológica que define la concepción de hombre hitleriano, y que apuesta a la identificación del Yo (principio abstracto) con 
el cuerpo (principio concreto). No obstante, esta identificación ha de ser tratada con precaución, con vistas a elucidar la noción misma de cuerpo que está en juego. Pues como resulta evidente para las filosofías educadas en la fenomenología, el cuerpo no sólo se determina en función de su extensión y objetivación (Körper), sino además en función de su trama sintiente e inobjetivable $(L e i b)^{7}$.

Es así, a partir de dicha identidad cuerpo-Yo, que podemos comprender además la expresión "mal elemental", con la que Lévinas califica en $1991^{8}$ el corazón del hitlerismo. Si el hitlerismo es un "mal", éste no reside en una anomalía o monstruosidad de la razón, sino en la exaltación de un monismo concreto. El monismo concreto del que hablamos, Lévinas lo tematiza en términos de una "adherencia" del Yo al cuerpo. A este respecto, el sentimiento elemental del que habla Lévinas, nace precisamente de esta "adherencia". El sentimiento elemental nace de esta matriz de la adherencia o del "encadenamiento" (LÉVINAS, 1997, p.19) del Yo al cuerpo.

\section{Hitlerismo o El SENTIMIENTO DE LA COMPACIDAD}

Para Lévinas, la novedad del hitlerismo reside en que éste es una empresa de destrucción de la libertad, que entra en flagrante contradicción con lo que nuestro autor nombra el "[...] espíritu de libertad” (LÉVINAS, 1997, p.8) de occidente. Se trata evidentemente de una definición in extenso de la noción de libertad, en la que cohabitan tanto formas de libertad espirituales como políticas, sean éstas cristianas, judías o bien aquella que atraviesa la “[...] promesa humanitaria de Marx" (LÉVINAS, 2006a, p.201). A su turno, lo que se decanta de esta afirmación inicial, es una comprensión sugerente de la libertad por parte de Lévinas, que en contraste con el hitlerismo, es concebida como posibilidad de volver a comenzar, como surgimiento de un renuevo. Todas estas formas occidentales del espíritu de libertad, comprometen precisamente la estructura de la novedad, de la invención, llámese ésta "perdón", "promesa” o "revolución”. La libertad es el poder de recomenzar infinitamente, es la forma de una renovación, cuestión que nos sugiere, desde ya, pensar que la libertad se estructura sobre el modelo de la

\footnotetext{
${ }^{7}$ Para una comprensión de la distinción fenomenológica entre Leib y Körper, remitimos aquí, entre otros, a los análisis de Paul Ricœur a propósito de la $5^{\text {a }}$ meditación, de las Meditaciones cartesianas de Husserl (RICCEUR, 2004)

${ }^{8}$ Se trata del Post-Scriptum que Lévinas escribiera para la edición norteamericana de Réflexions sur la philosophie de l'hitlerisme en 1991.
} 
apertura. En este sentido, el totalitarismo, en tanto filosofía de la no-libertad, no sólo apostaría a la imposibilidad de volver a comenzar, la imposibilidad del renuevo, sino además reposaría sobre el modelo de un cerramiento. Esta oclusión a la novedad, se articula en torno a dos tiranías: la del tiempo y la del cuerpo. Refirámonos a esta última, intentando ahondar en la trama afectiva que se decanta de ella: el sentimiento de encadenamiento.

Lévinas no puede ser más enfático al afirmar que, en tanto filosofía de la no libertad, el paradigma del totalitarismo es el paradigma del "encadenamiento", del "estar clavado", y de la sumisión voluntaria a ese encadenamiento, articulado por la matriz biológica del cuerpo, entendido éste en términos de lo objetivable. La novedad del hitlerismo, dirá Abensour lector de Lévinas, es "[...] la entrada en servidumbre" (1997a, p.44), y la tonalidad afectiva del hitlerismo, reposa o emana a partir de este encadenamiento.

Una sociedad basada en el vínculo biológico, consanguíneo, apuesta por la posibilidad de una sociedad homogénea y eventualmente "pura", sin contradicciones, que, negando y/o subsumiendo fatalmente las formas históricas del espíritu a la tiranía del cuerpo, se decanta en un principio de adherencia, que deviene en sumisión y servidumbre, como un modo aberrante, pero posible, de ser-en-el-mundo. Decíamos que Lévinas se refiere al hitlerismo en términos de una "filosofía de los sentimientos elementales", para así enfatizar la novedad de una perspectiva que moviliza una nueva disposición afectiva, la del encadenamiento, y que reposa sobre el primado otorgado al cuerpo biológico. Se trata del sentimiento de la adherencia del espíritu al espíritu, de su anclaje en una matriz biológica precisa e infranqueable. Así, en 1935 Lévinas escribía:

El cuerpo no es solamente un accidente desgraciado o feliz que nos pone en relación con el mundo implacable de la materia - su adherencia al Yo vale por ella misma. Es una adherencia a la cual uno no escapa y que ninguna metáfora sabría hacerla confundir con la presencia de un objeto exterior; es una unión en la que nada sabría alterar el gusto trágico de lo definitivo. (1997, p.18).

En cuanto anclaje "[al] cual uno no escapa", la posibilidad de la libertad entendida como renovación, como "libertad infinita en relación con toda atadura" (p.11), aparece como un imposible en esta matriz biológica, y bajo

\footnotetext{
9 Se trata de la noción de "Être rivé " que atraviesa el texto De l'évasion, de 1935, y que conviene leer en consonancia con el texto de 1934.
} 
este respecto el sentimiento de encadenamiento se condice perfectamente con una estructura de no-libertad. Por ello, continúa Lévinas,

[1] a esencia del hombre ya no reside más en la libertad, sino en una especie de encadenamiento. Ser verdaderamente uno-mismo, no es retomar su vuelo por encima de las contingencias, siempre extranjeras a la libertad del Yo; es al contrario, tomar consciencia del encadenamiento original ineludible, único a nuestro cuerpo; es sobre todo aceptar este encadenamiento. (p.18).

Por otra parte, este encadenamiento y /o sumisión del espíritu al cuerpo, este monismo concreto, con todo, no excluye, en el fondo, la idea de espíritu; más bien, opera ahí una lógica de identificación de éste con aquél. Esto es, la espiritualización del espiritu reside en esta identificación con el cuerpo, como si el espíritu se diseñara y limitara a partir de la opacidad concreta del cuerpo, determinando su arraigo y localización; espiritualidad engarzada en el cuerpo, del cual se puede predicar su vitalidad, tonicidad, fuerza, vigor, entre otros. Lévinas contrapone a la concreción vitalista del espíritu, una noción de espiritualidad fundada en "[...] la dignidad del pensamiento" (2006b, p.129), en el vuelo que la razón alcanza en "[...] el trabajo teórico de un matemático, de un físico" (p.127). La dignidad del hombre reside en su pensamiento, y en cuanto tal moviliza una noción de espiritualidad "[...] disociada de la materia inerte, pero también más allá de todo fenómeno biológico” (p.127). La identificación espíritu-cuerpo, la preponderancia de lo biológico aparece así como forma suprema del ideal espiritual nazi, y por ello, escribirá Lévinas en el año 1933,

Es difícil no darse cuenta que los partidos políticos extremistas, hoy en día poderosos en Alemania, están fascinados por esta noción de espiritualidad. Desconfían de la razón, pues ella se opone a su vitalidad [...] Los alemanes creen que el dolor es más real que la razón que quiere asfixiar el dolor, y que la verdad no sale de la observación imparcial de las ideas eternas, sino que ella es un grito horroroso de la existencia en lucha por su sobrevivencia [...] (p. 132).

Asimismo, resulta relevante destacar que la estructura unidimensional de la existencia, como imagen del cuerpo-uno, concuerda con la representación totalitaria del pueblo-uno, en términos de una estructura de la "compacité"(ABENSOUR, 1997b), de lo macizo, que apuesta a una "[...] cohesión absoluta" (p.53), a una fusión de lo social, y que por tanto niega la "división", esto es, la diversidad, la heterogeneidad, como constitutiva de la sociedad; estructura que vive bajo el embrujo de una sociedad homogénea, 
compacta, reconciliada, pura; que no concibe la distancia y separación social, que repele y "[...] pone fin a todo heroísmo" (LÉVINAS, 1997, p.21), y que bajo este respecto, rechaza y expulsa, hasta la eliminación a través del asesinato, toda forma de alteridad social. Con relación a un propósito similar, Claude Lefort, escribe: "Todo se presenta como si el cuerpo debiera cerciorarse de su identidad propia expulsando sus desechos, o bien como si debiera cerrarse sobre sí mismo sustrayéndose al afuera, conjurando la amenaza de efracción que hace pesar sobre él la intrusión de elementos extrańos" (1990, p.72).

Desde un punto de vista de la lógica de la identidad, la estructura del encadenamiento muestra el privilegio de un entramado unidimensional de sentido, toda vez que el cuerpo biológico, objetivable, funciona como horizonte de sentido insuperable en el proceso de identificación. El yo que se decanta de la estructura del encadenamiento es tributario de un esquema centrípeto, de una lógica de vuelta a lo propio, de una serie de autoposicionamientos y procesos autorreferenciales. Lévinas describe esta situación en términos de una ontología de la presencia total, de la perseverancia en el ser, de un conatus essendi egoísta, "preocupado de si", inquieto por su propia supervivencia y territorio. Se trata de un "[...] imperialismo del Mismo [...] orden universal o totalitarismo” (LÉVINAS, 1994, p.76).

Lo patético de esta ontología del encadenamiento radical, inscrita en la forma del cuerpo-uno, estriba en la fatalidad de la identidad o la identidad como fatalidad, toda vez que ella traduce la imposibilidad de escapar, la imposibilidad de la evasión, la imposibilidad de darse lo otro, de abrirse a la novedad, so pena de delito de traición. Reconocemos aquí la matriz de la claustrofobia que anunciáramos anteriormente, y que diseña no sólo la estructura de la dominación totalitaria sino la estructura ontológica de toda forma de dominación en general, toda vez que ella traduce el esquema de una totalidad aplastante, de una presencia total. En este sentido, la significación de la claustrofobia no traduce tanto la forma de una asfixia, a la manera de una "falta de aire" superior, sino más bien ella entraña la forma de una plenitud excesiva. Lo que asfixia es la plenitud, lo desbordante. Así, es manifiesto el lenguaje en clave encierro y claustrofobia de Lévinas en 1935; ser uno mismo es una forma de inmovilización amenazante, se trata de un "[...] sentimiento agudo de estar clavado", la "[...] inamovilidad misma de nuestra presencia" (LÉVINAS, 1982a, p.95), "[...] imposibilidad radical de escaparse a uno mismo [...] presencia irremisible del yo a sí mismo" (p.112). La identidad como encadenamiento, asfixia y claustrofobia, puede entenderse también a la 
luz de una tiranía del tiempo en la medida que la matriz del encadenamiento traduce un presente interminable e imperdonable, que no deviene, que no se altera, que no muere. Este esquema temporal puede comprenderse con claridad a la luz de Humanismo del otro hombre (LÉVINAS, 1972), en donde distinguiendo la temporalidad de lo "actual" y de lo "inactual" - que es la temporalidad propiamente humana - Lévinas insiste en el carácter sin alteración y sin devenir de lo actual, que es la forma lógica del concepto y de la identidad, que vira en una "[...] presencia total", forma acabada de la "gesta del ser", "del ser en si”" como "[...] síntesis de presentes" (p.8). La presencia total, a la manera de una indistinción entre el día y la noche, incuba una forma de violencia particular, tributaria del paradigma de la dominación, violencia de lo actual, del poder, dirá Lévinas, que es "[...] hija de Hitler" (1972, p.11).

La estructura de la dominación totalitaria nazi, es así la forma de un cerramiento a toda forma de exterioridad, social, temporal, a toda forma de alteridad. Es esta estructura de cerramiento, propia del totalitarismo, que bajo la pluma de Miguel Abensour es comprendida como la imposibilidad de la utopía: "[...] una sociedad sin utopía, privada de utopía es exactamente una sociedad totalitaria" (2000a, p.19)

Sabemos que si Abensour se esfuerza en romper con la asociación entre totalitarismo y utopía, llevada a cabo por algunos pensadores contemporáneos, insistiendo en la tesis según la cual el totalitarismo conlleva la destrucción del espacio político, es porque la utopía es pensada desde un comienzo como la entrada al tiempo de la política, en el que las nociones de exterioridad, tiempo o alteridad adquieren una dignidad filosófica relevante. Por su parte, y si bien es cierto el hitlerismo para Lévinas se entronca perfectamente con esta idea de cerramiento a la exterioridad, enclaustramiento decíamos, nuestro autor afirmará de manera enfática que el totalitarismo es mucho más que la negación de la temporalidad política, se trata de la negación de lo humano sin más. El hitlerismo, escribe Lévinas al final del texto de 1934, no "[...] cuestiona solamente algún dogma de la democracia, del parlamentarismo, o de política religiosa. [El hitlerismo] cuestiona la humanidad misma del hombre" (p.24). Lo que resta esencial aquí es, por una parte, que la negación de lo humano, en sentido levinasiano, es precisamente negación de la exterioridad, tiempo y alteridad, que son nociones claves para la comprensión de lo humano y más ampliamente del encuentro con los otros. Pero por otra parte, la cuestión de lo humano es además tematizada en Lévinas en clave utópica, como forma de un no-lugar, para recoger en ello una dimensión estrictamente ética del encuentro 
interhumano, exterior a la política. Por ello, podemos decir con Lévinas que si una sociedad totalitaria niega lo humano, indefectiblemente niega la utopía.

\section{UTOPÍA O EL SENTIMIENTO DE LA SEPARACIÓN}

L'infini ne se présente à nous que sous l'aspect de l'indéfini. (Auguste Blanqui)

Lévinas piensa la utopía como forma de un social infinitamente abierto a la heterogeneidad de las formas, a la multiplicidad humana, en una palabra, a la alteridad. En contraste con la forma cerrada y oclusiva de la fusión totalitaria, forma obstructora y negadora de lo otro, el registro de la utopía en Lévinas aparece exactamente como lugar de una des-clausura, de una suspensión o interrupción de la ontología del encadenamiento; ella se diseña como una pausa, o epojé de la gesta del ser, del conatus del "estar clavado". Si la utopía es imposible en una estructura totalitaria, si ella es lo contrario del enclaustramiento, de la comunidad pensada como fusión, es porque ella es la entrada en el registro de lo humano, "[...] utopía de lo humano" (LÉVINAS, 1990, p. 77). En la perspectiva levinasiana, la elucidación de dicho registro tiene que ver con una semántica de la apertura, de la exterioridad, de lo otro. A este respecto, la utopía cobra matices de un orden sumamente acotado, que no podría entroncarse con la trama de tradiciones utópicas, según las cuales utopía podría significar proyección de un mundo imaginario, o lugar donde todo es perfecto o bueno. Para Lévinas la utopía "[...] no es "sueño" ni "porción” [lot], (LÉVINAS, 2002, p.28), esto es, ella no refiere un espacio quimérico, o determinado; un lugar, una extensión o recorte espacial. $\mathrm{Ni}$ sueño ni lugar, utopía refiere la concreción de lo humano, ella es "[...] el claro [Clairière] donde se muestra el hombre" (p.28).

En el pensamiento de Lévinas, sabemos que lo humano atañe a un registro de sentido estrictamente fuera de la gesta del ser, fuera de la lógica del lugar, lo sin topología, y por ello lo humano es pura u-topia. Bajo este respecto, ¿es acaso el texto De l'évasion, cuyo núcleo argumentativo es el de la salida del ser, la antesala metodológica de la "utopía de lo humano"? ¿Sería posible leer en las líneas de De l'évasion el primer elogio al no-lugar como garante de un sentido otro? 
Al final de De l'évasion Lévinas escribe: "Toda civilización que acepta el ser [...] merece el nombre de bárbara” (1982a, p. 127), afirmación que conviene leerla - y es necesario insistir en ello - a la luz del acontecer histórico de los años 30 en Europa, en los que el ser se anunciaba como pesadez, como presencia sin reverso, "presencia total", decía Lévinas. En este sentido, "aceptar el ser" y su corolario de "civilización bárbara", es denunciar al mismo tiempo el peligro latente de la deriva política de la estructura ontológica, en particular cuando ésta es tributaria del esquema de la totalidad, o lo que es lo mismo, del sentido de la Filosofía reposando sobre el resorte de la totalidad. Se trata para Lévinas de indicarnos el singular sustrato "especulativo" (1976, p.80) que se decanta de esta racionalidad del hitlerismo, de esta "filosofía”, y de alertarnos sobre la posibilidad permanente y contemporánea de que todo "totalitarismo especulativo" conlleva la posibilidad de desembocar en un "totalitarismo político" (p.80). La cuestión es de envergadura; no sólo porque de la deriva del uno al otro, se juega la humanidad misma del hombre, la vida, sino además porque el totalitarismo político marca el "fin de la filosofía" (p.80). A luz de estas cuestiones, ¿qué resta por hacer cuando el ser del ente se despliega como plenitud de un sin sentido, como Il $y$ a, al punto de no poder ni siquiera morir ${ }^{10}$, cuando ninguna donación de sentido es posible ${ }^{11}$, cuando "Ninguna filosofía de la historia garantiza contra la vuelta de la barbarie"? (LÉVINAS, 1991, p.194). La respuesta de Lévinas es sin concesión: "Salir del ser" (1982a, p.97). Sin poder detenernos a restituir la totalidad de los análisis de este texto, baste con insistir en la noción de ser que allí se juega, entendido como forma de una plenitud de sin sentido aplastante, determinado por su época, en la que el hitlerismo se destilaba como un período de "[...] desesperanza ininterrumpida" (POIRIÉ, 1992, p.72), y en donde la existencia temporal se atestigua como un "absoluto" (LÉVINAS, 1982a, p.94) indeclinable, prescribiendo "[...] la inmovilidad misma de nuestro ser" (p.95). No obstante, este patetismo existencial, esta claustrofobia decíamos en páginas anteriores, está lejos de traducir un quietismo, un pesimismo mortal, al contrario, la plenitud del ser es al mismo tiempo la "[...] experiencia de una revuelta" (p.95) contra aquello que aplasta. De ahí entonces, la "necesidad de evasión”,

\footnotetext{
10 "Ahí donde el juego perpetuo de nuestras relaciones con el mundo es interrumpido, no encontramos, como podría uno pensar equivocadamente, ni la muerte, ni el 'yo puro', sino el hecho anónimo de ser. La relación con un mundo no es sinónimo de existencia. Ésta es anterior al mundo. En la situación del fin del mundo se plantea la relación primera que nos ata al ser" ( LÉVINAS, 1998, p.26).

11 "Ninguna generosidad, que contendría, al parecer, el término alemán es gibt, correspondiente al hay se manifestó entre 1933 y 1945. ¡Esto debe ser dicho! La luz y el sentido nacen sólo con el surgimiento y la posición de existentes en esta horrible neutralidad del hay" (LÉVINAS, 1984, p.407).
} 
expresión que como sabemos, articula las apuestas teóricas de este pequeño gran libro.

La revuelta contra el ser - la salida del ser - puede ser comprendida en términos de una "Interrupción ontológica" (LÉVINAS, 1998b, p.25), determinando así no sólo el momento de la suspensión del juego del ser, cese de la claustrofobia, sino en particular el momento del advenimiento de un régimen de sentido extravagante al ser, que no es "refugio" (LÉVINAS, 1982a, p.71) ni búsqueda de un pliegue reparador en la dinámica de la plenitud del ser, de su "brutalidad y seriedad" (p.70), sino salida, sin retorno, del ser. Nos parece extremadamente importante comprender la idea de interrupción desligada de una lógica del refugio, pero también de la tentación, siempre apresurada, a nuestro juicio, de nombrar al otro. El problema de la evasión no apunta, en lo inmediato, al problema de la responsabilidad para con el otro, que es un motivo que comienza a perfilarse en los ańos 40, sino al problema de la libertad, de "[...] la libertad humana y el hecho brutal del ser que la golpea" (p.67) Así, en la evasión ninguna ontología de la protección hemos de leer allí, sino más bien una gestualidad que subvierte esa lógica del resguardo y de la interioridad, para aproximarnos a los bordes de un más allá del ser, al registro de una exterioridad, de una transcendencia sin protección, sin reflejo en ninguna interioridad. En otros términos, la exterioridad a la que apunta la direccionalidad de la evasión, como forma de un más allá del ser, no refiere un "[...] quelque part" (p.73), no indica una nueva geografía; tampoco indica una noción de trascendencia reposando sobre el esquema del ser finito, pues la evasión no es "[...] huida hacia la muerte" (p.76). Al contrario, la necesidad de evasión, pone de manifiesto, a nuestro juicio, la imposibilidad de la domiciliación del ser del ente, así como la imposibilidad de una correlación entre la trascendencia que abre la evasión y la inmanencia que ella rompe. La evasión se decanta y prolonga en la interdicción de todo topos tendiente a limitar el contenido de su destino, el más allá del ser. Esta "filosofía de la evasión" según la expresión de Lévinas, se instala así en las antípodas de toda tentación de topología que sería insistir en la persistencia de nuestro ser en un lugar; la evasión no nos conduce hacia la "eternidad" dirá Lévinas, que sigue siendo tributaria "[...] del ser clavado a sí mismo" (p.95). ¿Es acaso la evasión un pasaje a lo indeterminado, a un no-lugar en sentido fuerte? ¿Es acaso la evasión el gesto metódico inaugural y necesario donde la "utopía de lo humano" podría hundir sus raíces? Lo único que podemos aventurarnos a decir sobre este no-lugar al que apunta la evasión, y que marca la ruptura de la claustrofobia, es que diseńa una zona marcada por la inquietud, por el 
no reposo, y ello pues la evasión "[...] pone en cuestión precisamente esta pretendida paz consigo mismo, pues ella aspira romper el encadenamiento del yo al sí mismo" (1982a, p.74) ¿Cuál es el destino de aquella "inquietud" en la obra posterior de Lévinas?

Creemos haber avizorado el destino indeterminado al que nos conduce la evasión, a la luz de la noción de interrupción, así como haber vislumbrado la tonalidad de la "inquietud" como lo propio de esta zona más allá del ser, de esta ruptura ontológica. Inquietud que bien podría ser pensada como la tonalidad afectiva no de la perseverancia del ser, sino de su suspensión, que coincide con la significación de la subjetividad humana, que es "desencajamiento" (LÉVINAS, 1998b, p.25) del ser. Tomada en su conjunto la reflexión de Lévinas, podríamos pensar que la obra de la ruptura ontológica y su corolario de no-lugar, tematizada en profundidad posteriormente por Lévinas, y como sabemos, por la estructura de la responsabilidad para con el otro, hace vibrar en una misma sintonía "inquietud" (LÉVINAS, 1982b, p.107) y no- lugar, u-topía. En efecto, la subjetividad como inquietud, es lo que denota la condición humana que es en rigor una "[...] incondición humana" (p.107), toda vez que ella se articula en consonancia con la trama de la responsabilidad. La responsabilidad para con el otro comienza a partir de esta, y por así nombrarla, radical epojé ontológica, momento en el que la "[...] condición ontológica [de lo humano] se deshace” (p.107.) en provecho de la acogida ética del otro. Esta concepción de una subjetividad fuera de la gesta del ser, es caracterizada exactamente en términos de una "[...] concepción utópica" (p.107) en el sentido que ella se define, en sentido fuerte, por una inversión de la perseverancia en lo de sí - fin de la claustrofobia - hacia la "inquietud" del De otro modo que ser.

Intentemos precisar el esquema afectivo de la utopía de lo humano. Según decíamos anteriormente, la estructura totalitaria reposa sobre la ficción de la pureza, evacuando de sí toda forma de alteridad. La producción de lo social que de aquí emana, se decanta en un esquema afectivo del orden del encadenamiento, de la fusión de lo social; o mejor dicho, de lo social como fusión. En contraste con esta afectividad de la fusión, de la compacidad, es posible situar la utopía del lado de un vínculo interhumano particular, que podríamos calificar preliminarmente en términos de "asociación afectiva”, fundado en la inquietud, y que en cuanto tal repele la aglutinación indistinta, intentando mostrar con ello un tipo de socialidad sin fusión ni jerarquía, y que distingue el social ético de Lévinas. En efecto, recordemos que la socialidad para Lévinas da cuenta de una experiencia que no se reduce a la forma de un saber, más aún, ella "[...] se 
opone a todo saber" (1996, p.27), ambicionando con ello situar el registro de lo humano en las antípodas de un social sujeto a cálculo, previsión y objetivación. De ahí la insistencia de Lévinas en pensar el vínculo interhumano en términos de encuentro, que pone el acento en las infinitas posibilidades siempre abiertas - y riesgosas- de toparme con los otros, en registros y geometrías indefinidas, enfatizando la socialidad con otros y el otro que Lévinas declina en términos de “[...] no-lugar, fuera del lugar” (LÉVINAS, 1990, p.131), o u-topía. De esta manera, en consonancia con Abensour, pensamos que si la utopía en sentido levinasiano es tributaria del registro del encuentro, la utopía puede ser pensada en el horizonte "[...] del afecto o del sentimiento" (ABENSOUR, 1991, p.575); registro del "[...] sentimiento [que] no es conocimiento" (LÉVINAS, 2006a, p.94) ¿Cuál es la tonalidad afectiva de la utopía? ¿En qué consiste?

Al sentimiento de la compacidad podemos oponer el sentimiento de la separación, como lo propio de una socialidad sin fusión, socialidad ética en el lenguaje levinasiano o utópica. Esta idea de la separación como fundamento de la socialidad o la intersubjetividad, reposa a su turno sobre una comprensión particular de la noción de sensibilidad que teje la subjetividad, y que permite a nuestro autor plantear la subjetividad en términos de "unicidad" (LÉVINAS, 1990, p.21). Ahondando en una noción de subjetividad sensible, y por ello única, Lévinas plantea al mismo tiempo no sólo la posibilidad de una intersubjetividad sin pretensión de homogeneidad, sino además, y porque se trata de seres únicos, nuestro autor concibe un principio de desagregación como lo propio de esta socialidad. Lo relevante a comprender aquí es que las unicidades no devienen totalidad, se asocian sin difuminarse, se encuentran desagregándose infinitamente; ellas conforman lo que Lévinas comprende como multiplicidad o pluralismo de lo social, "[...] los únicos son multiplicidad" (POIRIÉ, p.86), y es por ello que la subjetividad no es una noción de participación sino de separación. De ahí se sigue también, que la noción de intersubjetividad que aquí aparece, supone una relación cuyos términos, Yo / Otro, se piensan por fuera de una correlación ontológica, esto es, por fuera de un común capaz de unir y ligar los términos de la relación. La multiplicidad de únicos, la posibilidad de un nosotros en el que todos los unos destaquen, en ello consiste la original apuesta de Lévinas, pues "[e]l ser entre nosotros, a saber, el ser separado, es mucho más que el ser unido" (LENGER, 1995, p.67) La distancia intersubjetiva es así el fundamento de una forma social productora de heterogeneidad, de multiplicidad de la alteridad. Asimismo, digámoslo de paso, esta distancia o separación intersubjetiva que como sabemos fundamenta la ética levinasiana, no es ni buena ni mala, no prescribe modos de ser para con los otros. Ella califica un desnivelamiento ontológico, asimetría o 
desigualdad intersubjetiva dirá Lévinas, piedra angular para un social sin fusión, y lo que es más determinante aún, única posibilidad, la del ser-separados, al parecer, de romper con la lógica de la dominación. Por ello Lévinas podrá decir: "Es necesario encontrar al hombre un parentesco distinto de aquel que lo une al ser lo que permitirá tal vez - pensar esta diferencia entre yo y el otro, esta desigualdad, en un sentido absolutamente opuesto a la opresión" (1990, p.272). Desigualdad de lo humano, diferencia entre yo y el otro, separación según el lenguaje de Totalidad e Infinito, que Lévinas la califica como "[...] indiferencia ontológica ” y que no obstante, constituye la posibilidad de la ética como "[...] no-indiferencia por el otro " (1990, p.273).

Asimismo, la subjetividad sensible, unicidad excepcional, sin reflejo ni parte en un todo social, aparece como un indiscernible, pues ella es "unicidad sin lugar" (Ibid., p.21), perfilando así su dimensión anti-tópica, o si se prefiere, u-tópica. De esta manera, la "utopía de lo humano" busca nombrar por sobre todo la inquietante geografía de la alteridad, exponiéndola a una semántica que no podría reducirse a una filosofía de la diferencia que sigue siendo tributaria de un esquema de oposición lógica (lo otro diferente a lo mismo), sino más bien disponiéndola en una semántica de la excepcionalidad, y en este sentido imposible de territorializar. Son varias las perspectivas de análisis las que se abren aquí. Por una parte, la subjetividad deja de ser una noción de límite o contorno, distinguible en un plano, para abrirse ella misma a la trama de la sensibilidad, portadora de intensidades sin contorno, pasaje a lo indeterminado, a la exterioridad sin revés. Podemos ver aquí el fin de la claustrofobia. Por otra parte, si se apuesta a una intersubjetividad entre seres separados y no limitados, de alguna manera habría de poder describirse el encuentro entre unicidades que no totalicen. ¿Qué tipo de relación puede establecerse entre seres separados? Lévinas tematiza esta socialidad en términos de "proximidad" (1990, p.129), como forma de un vínculo marcado por la distancia intersubjetiva. La proximidad sólo se predica de la separación cuyo dinamismo refracta toda jerarquía, y por lo mismo pone a distancia la posibilidad de la opresión que sigue siendo una noción de fijación; y ello debido a que la separación es fuente de "inquietud" (p. 131). Esta "inquietud", es decir, lo sin reposo, prohíbe así la petrificación topológica y espacial del vínculo intersubjetivo, ella es la garante de la distancia interhumana. Esta "inquietud" es así tributaria de la asimetría, refractando toda posible "sincronía” (p.136) o "simultaneidad" (p.136), abriéndose a una trama de la "desmesura" (p.114), o de lo indeterminado. Esta cuestión es tremendamente relevante en la medida que la socialidad utópica, en rigor no nos dice nada sobre la calidad del vínculo 
que pudiera hacer derivar el significante utopia en eu-topía. Bajo el signo de utopía Lévinas intenta señalar una cierta especificidad de lo humano, noción abierta, llena de riesgos, donde no caben promesas, y cuyo topos se presenta como irreductible a la lógica del saber y /o del Ser, nociones ambas que, bajo la óptica de Lévinas, funcionan como estructuras de sentido no sólo asimiladoras y alienantes de la alteridad de lo humano, sino además como posibilidad de territorializar, localizar y dominar la alteridad. Se trata para Lévinas, de insistir en la dimensión utópica de lo humano, cuyo topos se declina según un modo que consiste en escapar justamente a todo topos, determinando una intersubjetividad cuya especificidad no podría diseñarse en virtud de un principio de fijación o de claustración tendiente a definir esta socialidad primera, salvaje. Se trata de una comprensión de lo social diferente "[...] de la ocupación de un lugar, de un construir, de un instalarse" (LÉVINAS, 1990, p.278), diferente del ser en común; más bien, el principio estructurante de esta forma de socialidad consiste en una permanente "des-claustración" de nuestro ser, esto es, en una salida de las formas clásicas que definen y acotan nuestro ser a un régimen territorial, topológico. Proponer la subjetividad como lugar de abertura, como desclausura y no-lugar, es al mismo tiempo pensar la subjetividad como "utopía" (p.279), forma de lo que no puede estar "enmurallado" (p.279), ni "encerrado en un lugar" (p.279), y por ello mismo indiscernible o separado, escamoteando indefinidamente la tentación de la fusión.

OLIVARES, Claudia Gutiérrez. Totalitarian fusion and utopian separation. Reading of Emmanuel Levinas and Miguel Abensour. Trans/Form/Açāo, Marília, v. 37, n. 1, p. 33-50, Jan./Abril, 2014.

\begin{abstract}
This articule attemps to clarify the unique social structure, which defines utopia in Levinas's thought, emphasizing its structural antagonism to the social form of the totalitarian structure. We argue that Levinasian utopia, as social form, is founded on the matrix of the "intersubjective separation". Hence, under this relation, the Levianasian utopia appears as a dimension that is radically opposed to the social structure of totalitarianism, where the "intersubjective separation" is impossible. The social being of utopia in Levinas is separation, whereas in totalitarianism the social being is agglutination. While the utopia separates the totalitarianism fuses together. Our approach will be supported with analytical elements drawn from Miguel Abensour's work about utopia. Thus, we assume Miguel Abensour's critical-political perspective of analysis as our own; consequently the critique of totalitarianism is determinant for the clearing of the utopian dimension.
\end{abstract}

KEYWORDS : Lévinas. Abensour. Totalitarianism. Utopia. Phenomenology. 


\section{Bibliografia}

ABENSOUR, Miguel. Emmanuel Lévinas, l'intrigue de l'humain. Entre métapolitique et politique. Entretiens avec Danielle Cohen-Lévinas. Paris : Herman, 2012.

ABENSOUR, Miguel. Pour une philosophie politique critique. Paris: Sens \& Tonka, 2009.

ABENSOUR, Miguel. Philosophie politique critique et émancipation ? In: La philosophie et l'émancipation de l'humanité. Paris, no 10, 29-77, 2002.

ABENSOUR, Miguel. L’utopie de Thomas More à Walter Benjamin. Paris: Sens \& Tonka, 2000a.

ABENSOUR, Miguel. Le procès des maîtres rêveurs. Paris : Sulliver 2000b.

ABENSOUR, Miguel. El mal élémental. In : LEVINAS, Emmanuel. Quelques réflexions sur la philosophie de l'hitlérisme Paris: Éditions Payot \& Rivages, 1997a.

ABENSOUR, Miguel. De la compacité. Architectures et régimes totalitaires. Paris: Sens \& Tonka, 1997b.

ABENSOUR, Miguel. Penser l'utopie autrement. In : CHALIER, Catherine; ABENSOUR, Miguel. Cahier de L'Herne. Emmanuel Lévinas. L’Herne : Éditions de L’Herne, 1991.

GHEORGHIU, C.Virgil. La hora veinticinco. Buenos Aires: Emecé, 1950.

LEFORT, Claude. La invención democrática. Buenos Aires: Nueva Visión, 1990.

LEIBOVICI, Martine. Claustrophobie du soi et besoin d'excedance. Le "pathétique du liberalisme" selon Emmanuel Lévinas. In: COLOQUIO INTERNACIONAL CHILE FRANCIA: Emancipación y movimientos sociales. Universidad Academia de Humanismo Cristiano, Santiago de Chile, 2012 (conferencia inédita).

LENGER, H.J. Emmanuel Lévinas: Visage et violence première. In: MÜNSTER, A. La différence comme non-indifférence. Ethique et altérité chez Emmanuel Lévinas. Paris: Kimé, 1995.

LÉVINAS, Emmanuel. Los imprevistos de la historia. Salamanca: Sígueme, $2006 a$.

LEVINAS, Emmanuel. La compréhension de la spiritualité dans les cultures française et allemand [1933]. Cités, Paris, n²5, 2006b.

LEVINAS, Emmanuel. Paul Celan, de l'être à l'autre. Paris: Fata Morgana, 2002.

LEVINAS, Emmanuel. En découvrant l'existence avec Husserl et Heidegger. Paris: Vrin, 2001.

LEVINAS Emmanuel. De l'existence à l'existant. Paris: Vrin, 1998a.

LEVINAS, Emmanuel. De dieu qui vient à l’idée. Paris: Vrin, 1998b.

LEVINAS, Emmanuel. Liberté et commandement. Paris: Le livre de Poche, 1994.

7 LEVINAS, Emmanuel. Quelques réflexions sur la philosophie de l'hitlérisme. Paris: Éditions Payot \& Rivages, 1997.

LEVINAS, Emmanuel. Transcendance et intelligibilité. Genève: Labor et Fides, 1996. 
LEVINAS, Emmanuel. Entre nous. Essais sur le penser-à-l'autre. Paris: Le Livre de Poche, 1991.

LEVINAS, Emmanuel. Autrement qu'être ou au-delà de l'essence. Paris: Le Livre de Poche, 1990.

LEVINAS, Emmanuel. Difficile Liberté. Paris: Le Livre de Poche, 1984.

LEVINAS, Emmanuel. De l'évasion. Paris: Le Livre de Poche, 1982a.

LEVINAS, Emmanuel (1982a), Éthique et Infini. Paris : Fayard, 1982 b.

LEVINAS, Emmanuel. Noms Propres. Paris: Fata Morgana, 1976.

LEVINAS Emmanuel. Humanisme de l'autre homme. Paris: Fata Morgana, 1972.

POIRIE François. Emmanuel Lévinas. Entretiens. Paris: La Manufacture, 1992.

RICCEUR, Paul. A l'école de la phénoménologie. Paris: Vrin, 2004. 